\title{
EXPERIMENTAL STUDY OF WIPER OPERATION BASED ON FOUR BAR MECHANISM
}

\author{
A.S. Abrar Ahmed, V. Ayush Kumar, S. Gokul, P. Vijay \\ UG students \\ Department of Mechanical Engineering \\ Panimalar Institute of Technology \\ Poonamallee, Chennai-600 123
}

\author{
C. Parthasarathy \\ Assistant Professor, \\ Department of Mechanical Engineering, \\ Panimalar Institute of Technology \\ Poonamallee, Chennai-600 123
}

\begin{abstract}
This project has been brought forward by using four bar mechanism in the existing wiper operation. The existing wiper operation is carried out majorly through slider crank mechanism. In the existing mechanism the rotary motion from the motor is converted into linear movements which increases the space constrain, whereas in the four bar mechanism the rotary motion is converted into rotary, translating and angular movements. By using the four bar mechanism in the existing wiper operation the space constrain is much reduced and the same angular output for the wiper can be produced even with smaller length ratio of links. With the use of a single blade wiper a maximum viewing angle is made to be covered. The operation angle that is produced in slider crank mechanism is also produced in four bar mechanism using smaller link lengths which reduces the total space constrain.
\end{abstract}

Keywords - wiper operation, four bar mechanism, slider crank mechanism, single blade wiper, space constrain.

\section{INTRODUCTION}

A windscreen wiper is a device used to remove rain, snow, ice and debris from a vehicle front. Almost all motor vehicles including cars, buses, trucks, locomotives, and watercraft with a cabin and some aircraft are equipped with one or more such wipers, which are usually a legal requirement. A wiper generally consists of a metal arm; one end pivots, the other end has a long rubber blade attached to it. The arm is powered by a motor, often an electric motor, although pneumatic power is also used for some vehicles. The blade is swung back and forth over the glass, pushing water, other precipitation, or any other impediments to visibility, from its surface. On vehicles made after 1969 , the speed is normally adjustable, with several continuous speeds, and often one or more intermittent settings. Most personal automobiles use two synchronized radial-type arms, while many commercial vehicles use one or more pantograph arms on some vehicles, a windscreen system is also used to improve and expand the function of the wiper(s) to dry or icy conditions. This system sprays water, or an antifreeze window washer fluid, at the windscreen using several well-positioned nozzles. This system helps remove dirt or dust from the windscreen when it is used in concert with the wiper blades. When antifreeze washer fluid is used, it can help the wipers remove snow or ice. For these types of winter conditions, some vehicles have additional heaters aimed at the windows, or embedded heating wire(s) in th glass; these defroster systems help to keep snow and ice from building up on the windscreen. Less frequently, miniature wipers are installed on headlights to ensure that they function optimally.

\section{FOUR BAR MECHANISM}

\section{A. Mechanism overview}

A four-bar linkage is the simplest movable closed chain linkage. It consists of four bodies, called bars or links, connected in a loop by four joints. Generally, the joints are configured so the links move in parallel planes, and the assembly is called a planar four-bar linkage. Spherical and spatial four-bar linkages also exist and they are used in practice. 


\section{International Journal of Engineering Applied Sciences and Technology, 2020 \\ Vol. 4, Issue 10, ISSN No. 2455-2143, Pages 231-236 \\ Published Online February 2020 in IJEAST (http://www.ijeast.com)}

A pair is a joint between the surfaces of two rigid bodies that keeps them in contact and relatively movable. A pair is formed when two links are in contact with each other. If the motion between the links is completely or successfully constrained then the pair is known as kinematic pair.

Planar four-bar linkages are constructed from four links connected in a loop by four one-degree-offreedom joints. A joint may be either a revolute, that is a hinged joint, denoted by $\mathrm{R}$, or a prismatic, as sliding joint, denoted by P.

A link connected to ground by a hinged joint is usually called a crank. A link connected to ground by a prismatic joint is called a slider. Sliders are sometimes considered to be cranks that have a hinged pivot at an extremely long distance away perpendicular to the travel of the slider.

The link that connects two cranks is called a floating link or coupler. A coupler that connects a crank and a slider, it is often called a connecting rod.

There are three basic types of planar four-bar linkage depending on the use of revolute or prismatic joints:

1. Four revolute joints: The planar quadrilateral linkage is formed by four links and four revolute joints, denoted RRRR. It consists of two cranks connected by a coupler.

2. Three revolute joints and a prismatic joint: The slider-crank linkage is constructed from four links connected by three revolute and one prismatic joint, or RRRP. It can be constructed with crank and a slider connected by the connecting rod. Or it can be constructed as a two cranks with the slider acting as the coupler, known as an inverted slider-crank.

3. Two revolute joints and two prismatic joints: The double slider is a PRRP linkage. This linkage is constructed by connecting two sliders with a coupler link. If the directions of movement of the two sliders are perpendicular then the trajectories of the points in the coupler are ellipses and the linkage is known as an elliptical trammel, or the Trammel of Archimedes.

\section{B. Methodology}

A mechanism involving four links in which one of the links of a kinematic chain is fixed. The four bar mechanism is a single degree of freedom device. This means that if we know the angular velocity of just the input link, we can determine the angular velocities of the remaining two links (if all of the geometry is known, i.e. lengths and angles of the links).

The rotor is connected to initial link that acts as a crank. The axis of the crank is in line with the axis of the guiding link, which makes the angular movements. The initial or crank link and the guiding link is connected by a transmitting link. The base of the crank link or origin is fixed, that is one end of the link is fixed. The base end or the origin of the guiding link is also fixed, but here there are only angular movements of the link no complete revolutions are observed.

\section{Material}

The knowledge of materials and their properties is of great significance for a design engineer. The machine elements should be made of such a material which has properties suitable for the conditions of operation, in addition to this a design engineer must be familiar with the effects which the manufacturing processes and heat treatment have in the properties of the materials. Hence, Mild Steel was chosen.

Mechanical Properties of Mild Steel :

\begin{tabular}{llc}
\hline Mechanical property & value & unit \\
\hline Young's Modulus & 210 & $\mathrm{GPa}$ \\
Tensile Strength & 370 & $\mathrm{MPa}$ \\
Yield Strength & 7.11 & $\mathrm{MPa}$ \\
Poisson's ratio & 0.29 & - \\
\hline
\end{tabular}

Tab. (a)

\section{CALCULATIONS}

\section{A. Area diagram}

The total area covered by the given dimensions with the output work angle ranging from $45-135 \mathrm{deg}$ from the origin is given below with the following dimensions,

Crank - $39 \mathrm{~mm}$

Follower - $101 \mathrm{~mm}$

Rocker - $65 \mathrm{~mm}$ 
Ground link - $85 \mathrm{~mm}$

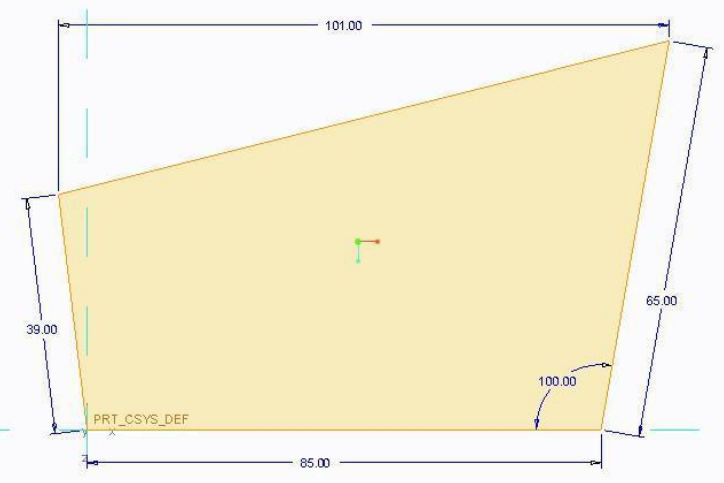

Fig. (a). Working area diagram

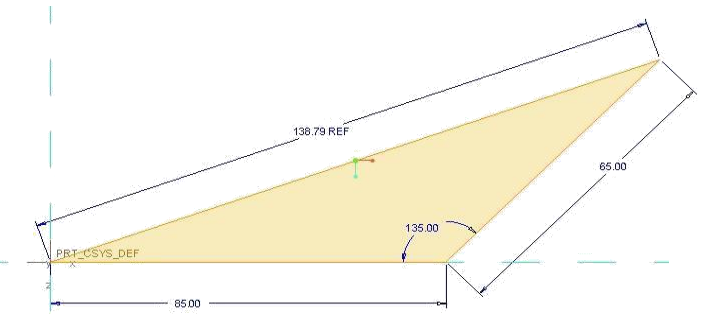

Fig. (b). Maximum area coverage

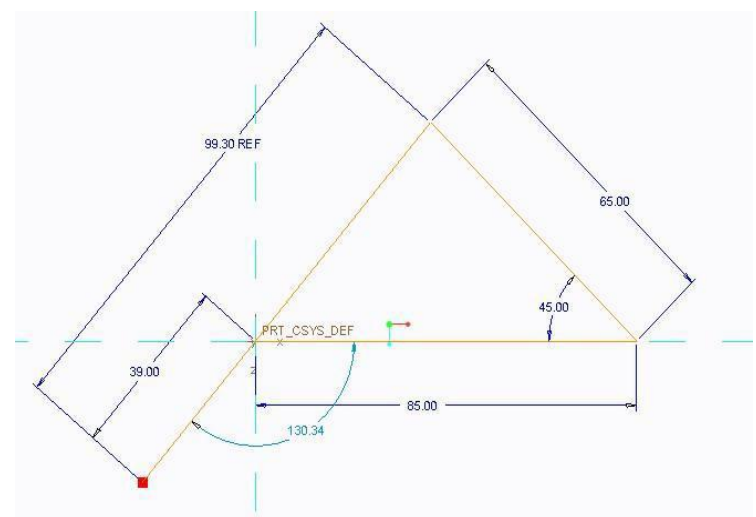

Fig. (c). Minimum area coverage

\section{B. Velocity diagram}

The velocity of the experiment is calculated for the maximum angle coverage of $135 \mathrm{deg}$, since the crank (input link) is in motion the velocity varies continuously and hence the input of the crank is taken as 39.80 deg based on the maximum angle coverage.

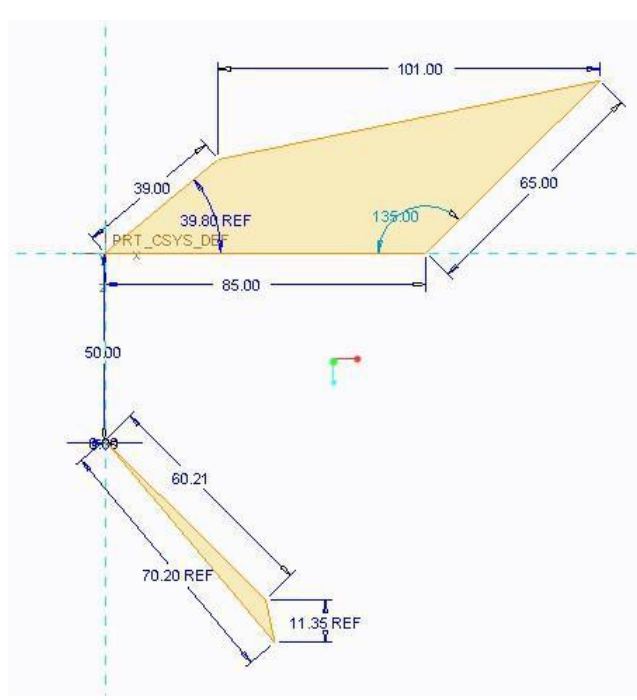

Fig. (d). Velocity diagram

\section{Formulae}

1) Angular velocity, $\omega=(2 \pi \mathrm{N}) / 60$

2) Linear velocity, $v=r \omega$

3) Angular velocity, $\omega=\mathrm{v} / \mathrm{r}$

4) Input speed required, $N=45 \mathrm{rpm}$

5) Input speed by motor max, $N=200 \mathrm{rpm}$

6) Let crank length, $r=39 \mathrm{~mm}$

7) By measurement length of $\mathrm{cd}=60.2 \mathrm{~mm}$

\section{Calculations}

1) Angular velocity, $\omega \mathrm{ab}=(2 \pi \mathrm{N}) / 60$

$$
\begin{aligned}
& =(2 * 3.14 * 45) / 60 \\
& =4.7 \mathrm{rad} / \mathrm{s}
\end{aligned}
$$

2) Linear velocity, $\mathrm{Vab}=\mathrm{r} \omega$

$$
\begin{aligned}
& =(0.039 * 4.7) \\
& =0.18 \mathrm{~m} / \mathrm{s}
\end{aligned}
$$

3) Linear velocity, $\mathrm{Vcd}=6.02 * 0.1$

$$
=0.602 \mathrm{~m} / \mathrm{s}
$$

4) Angular velocity, $\omega c \mathrm{~cd}=\mathrm{Vcd} / \mathrm{CD}$ 


\section{International Journal of Engineering Applied Sciences and Technology, 2020 \\ Vol. 4, Issue 10, ISSN No. 2455-2143, Pages 231-236 \\ Published Online February 2020 in IJEAST (http://www.ijeast.com)}

$$
=9.27 \mathrm{rad} / \mathrm{s}
$$

5) Max ang velocity of motor, $\omega m=(2 \pi \mathrm{N}) / 60$

$$
\begin{aligned}
& =(2 * 3.14 * 200) / 60 \\
& =20.94 \mathrm{rad} / \mathrm{s}
\end{aligned}
$$

\section{E. Standard values}

- Angle of operation standard $=67-110 \mathrm{deg}$

- Average angle $=90 \mathrm{deg}$

- $\quad$ Minimum speed of motor $=32 \mathrm{rpm}$

- $\quad$ Maximum speed of motor $=70 \mathrm{rpm}$

- $\quad$ Rated voltage of motor $=24$ volts

- Power rating $=40-130$ watts

- Minimum wipes per $\min =32$ wipes $/ \mathrm{min}$

- Average wipes per $\mathrm{min}=45 \mathrm{wipes} / \mathrm{min}$

- Maximum wipes per $\mathrm{min}=65$ wipes $/ \mathrm{min}$

- Motor torque $=13-120 \mathrm{Nm}$

- Motor type = D.C

- $\quad$ Power source $=24$ volt battery

- $\quad$ Motor weight $=1.5 \mathrm{~kg}$

\section{DESIGN OF FOUR BAR MECHANISM}

The setup is designed using Inventor 2019 for the stated dimensions and assembled to verify the kinematic simulation. The dimensions are as follows

Crank (A-A) - $39 \mathrm{~mm}$

Follower (A-A) - $101 \mathrm{~mm}$

Rocker (A-A) - $65 \mathrm{~mm}$

Ground link (A-A) - $85 \mathrm{~mm}$

Locker (dia) - $8 \mathrm{~mm}$

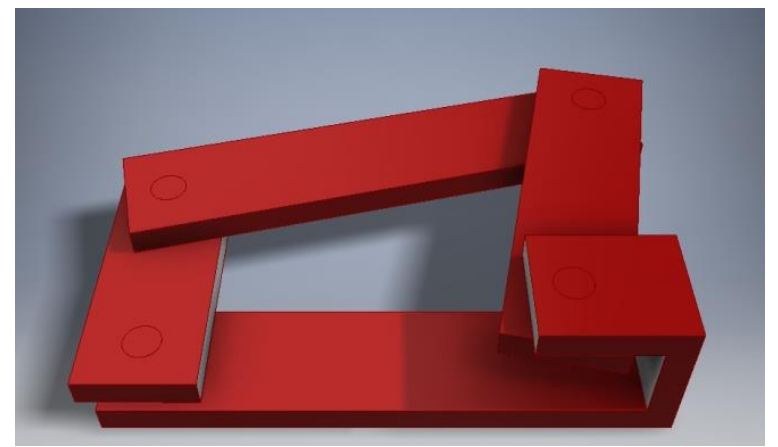

Fig. (a). Designed model

\section{FABRICATION AND WORKING}

The stand has been fabricated for 400 X 300 X 250 $\mathrm{mm}$. And the $\mathrm{C}$-section frame has been fitted with the stand and a $60 \mathrm{~mm}$ dia hole is drilled in the stand to fit the motor. An $8 \mathrm{~mm}$ dia chamfered hole is drilled in the $\mathrm{C}$ - section frame.

The links has been machined for the dimensions 39 $\mathrm{mm}, 101 \mathrm{~mm}, 65 \mathrm{~mm}$ (crank, follower, and rocker). The ground link is maintained as $85 \mathrm{~mm}$ from center of the motors rotor and the drilled chamfered hole center of the $\mathrm{C}$-section frame. On the opposite extreme sides of the links the chamfered hole has been drilled for $8 \mathrm{~mm}$. An extension bracket is welded over the $65 \mathrm{~mm}$ rocker link to limit the moments and guide the wiper arm.

The M8 bolt and nut is used to connect the links from the origin (motor) to the end (wiper). The setup is assembled by fixing up the links and mounting the motor in the stand within the drilled hole. And the wiper arm is fixed on the rocker bracket and the end of the wiper arm is connected to the $\mathrm{C}$-section frame.

The motor is then connected to the eliminator which converts the alternate current into direct current from $240 \mathrm{~V}$ to $12 \mathrm{~V}$, using the horn clips and connection wires.

The setup is turned ON and a trial run of the setup is made to analyze the movements of the links and output of the wiper. After the successive output analyzed from the setup, the links and parts are dismantled from the stand, and checked for any wear.

The links and parts are again assembled and fitted with the stand. To avoid the loosening of the links from the joints, the nut sided joints are welded and machined to avoid the collision. The protective layer of red oxide is coated over the stand and links as a base coat and to avoid rusting in welded joints.

The wiper arm is fitted inside the rocker bracket and the ends are connected with the $\mathrm{C}$-section frame. Then the wiper blade is fitted on the wiper arm. And the connections are given again to check for collision, wiper operation angle of the setup. 


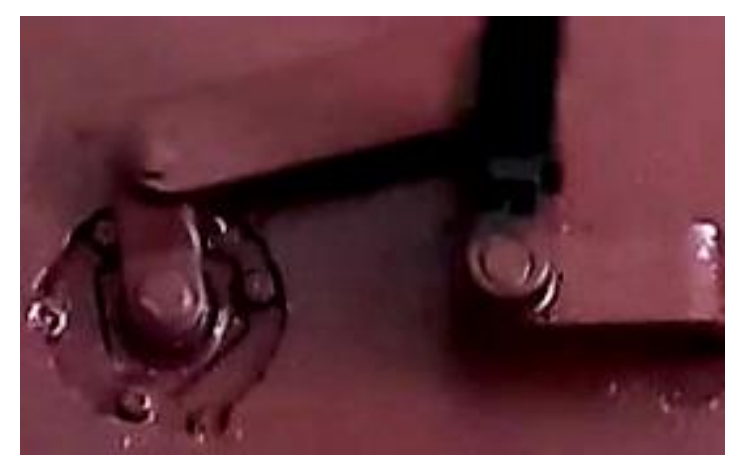

Fig. (b).Fabricated model

\section{PHOTOGRAPHIC REVIEW}

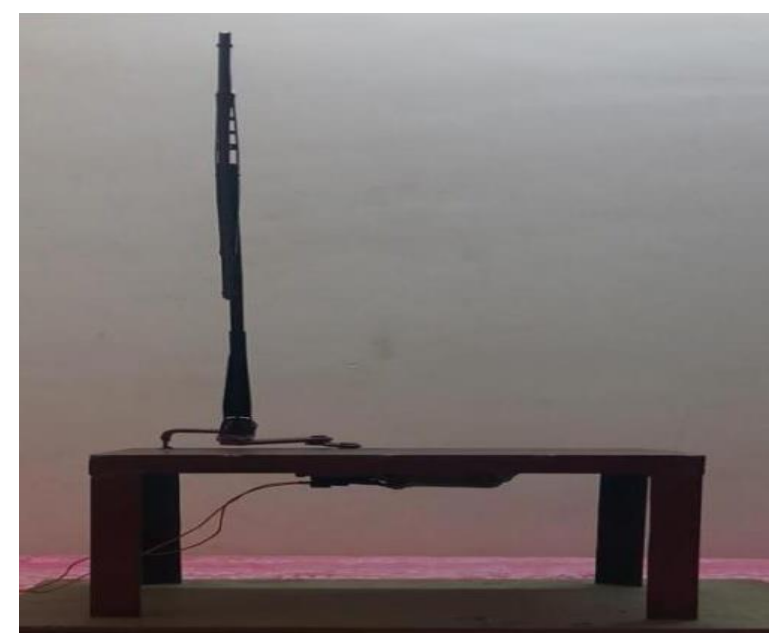

Fig. (a). Front view

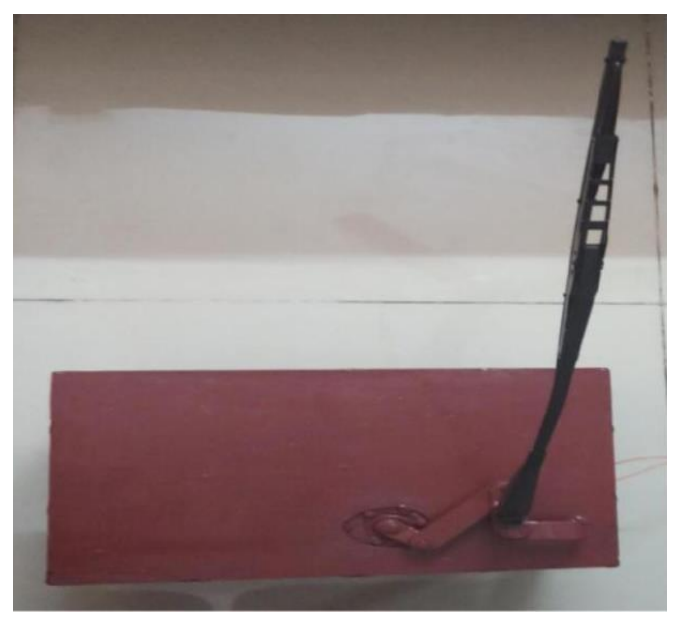

Fig. (b). Top view

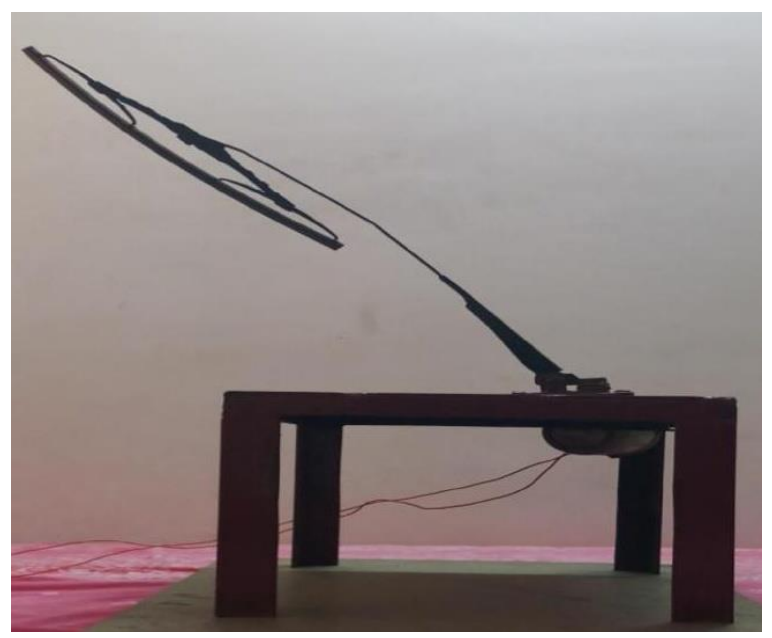

Fig. (c). Side view

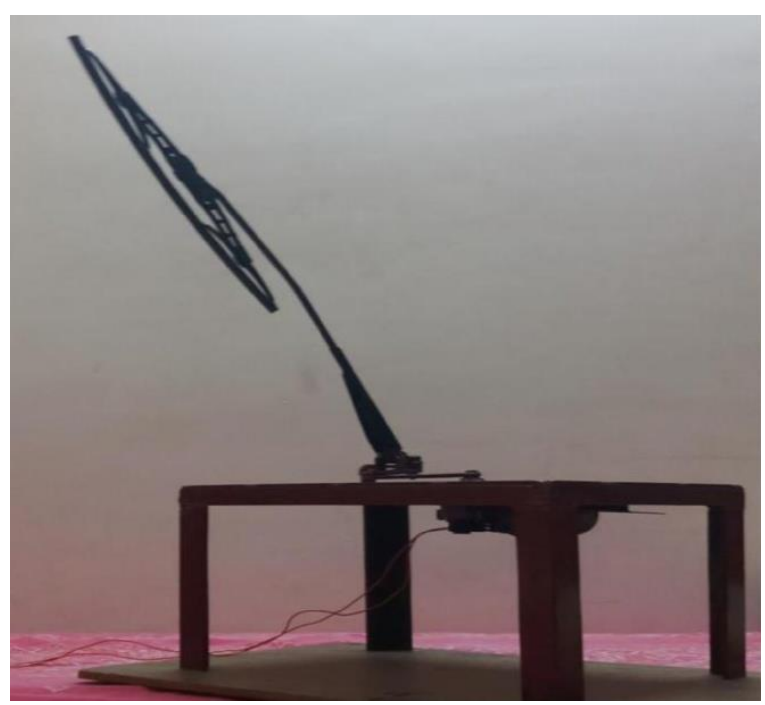

Fig.(d). Isometric view

\section{CONCLUSION}

The Assembling of manufactured parts has been carried our as per the design and a motor is connected to run the setup. After 2, 3 trails we altered the cyclic speed of the setup by changing the power input points to attain the desired speed. Calculations based on the input were formulated and analyzed. Finally our setup performs the assigned task. Here we conclude that "EXPERIMENTAL STUDY OFWIPER OPERATION BASED ON FOUR BAR MECHANISM", is a possible and efficient way to obtain the desired operational angle with a reduced setup size. 


\section{REFERENCES}

[1] B.S. Hsu, S.F. Ling "Windshield Wiper System Design"- International journal of vehicle design, vol 11, Issue 1,pp 6378,2003 .

[2] Imed Khemili,Lotfi Romdhane "Dynamic Behavior of a planar Flexible Slider-Crank Mechanism with Clearance"- European journal for mechanics, Vol 27,Issue 5, pp 882-898, September 2008.

[3] Luiz Fernando, Silva dos Santos, "Windshield Wiper System Life Improvement Using Overstress Testing to Determine the Product Weak Point". SAE Paper 2007-01-2660.

[4] Weixiang Li, Susumu Satoh, "Improvement of Wiping Ratio with Low-Speed By Use of Wide View Wiper System". SAE Paper 2004-01-0877.

[5] Cadirci. S, B. Selenbas and H. Gunes (2016a). Geometric Modifications to Minimize Lift Acting on a Simplified Front Windshield Wiper Blade. Journal of Thermal Science and Technology 36(2), 103-109.

[6] L. Li, Q. Li, Vibration Analysis Based on Full Multi-Body Model for the Commercial Vehicle Suspension System, Proceedings of the 6th WSEAS International Conference on Signal Processing, Robotics and Automation, 2003, pp. 203-207.

[7] N. Nagashima, R. Nishimura, R. Ochiai, G. Fujita, Construction of Highly-Accurate Simulation Model in Automobile's Power System, Proceedings of the 7th WSEAS International Conference on Electric Power Systems, High Voltages, Electric Machines, 2007, pp. 334-340.

[8] S. Vlase, H. Teodorescu, L. Scutaru, On the Form of the Motion Equations of the Multibody Systems with Elastic Elements, WSEAS Transactions on Systems, Vol. 6, No. 1, 2007, pp. 190-193.
[9] C. Alexandru, I. Barbu, Modeling the Windshield Wiper Mechanisms as MultiBody Systems, Proceedings of the IX IFToMM International Conference, 2004, pp. 29-34.

[10]E. J. Haug, K. K. Choi, J.G. Kuhl, J.D. Wargo, Virtual Prototyping Simulation for Design of Mechanical Systems, Journal of Mechanical Design, Vol.117, No.63, 1995, pp. 63-70.

[11] G. Romero, J. Maroto, M.L. Martinez, J. Felez, Training in Engineering Design using Virtual Prototypes, WSEAS Transactions on Computers, Vol. 5, No. 4, 2006, pp. 753762.

[12]Q. Shen, J. Gausemeier, M. Grafe, Virtual Prototyping: To Compose Mechatronic Systems in VR Environment, WSEAS Transactions on Computers, Vol.5, No.4, 2006, pp. 727-734.

[13]Z. Affi, L. Romdhane. ADAMS/SIMULINK Interface for Dynamic Modelling and Control Of Closed Loop Mechanisms, Proceedings of the 7th WSEAS International Conference on Automatic Control, Modeling and Simulation - ACMOS, 2005, pp. 353356.

[14] K. Gunnar, B. Vladislav, The Simulation of Electromechanical Drive with DC Motor, Proceedings of the 5th WSEAS International Conference on Power Engineering Systems ICOPES, 2005, pp.145-150. 